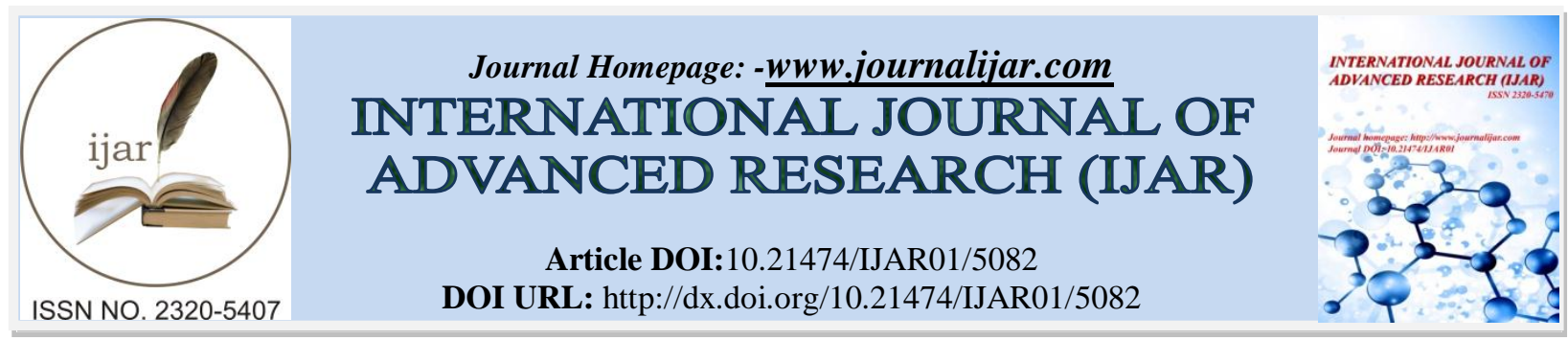

RESEARCH ARTICLE

\title{
AWARENESS, KNOWLEDGE AND ATTITUDE OF PREGNANT WOMEN TOWARDS HIV/AIDS IN TERTIARY CARE HOSPITAL: A COMMUNITY BASED STUDY.
}

\section{Uruj Jahan $^{1}$, Kavita Verma ${ }^{1}$, Shruti Gupta ${ }^{1}$, Seema Dwivedi ${ }^{2}$ and Anuradha yadav $^{3}$.}

1. Lecturer, Department of Obstetrics and Gynecology, GSVM Medical College, Kanpur, Uttar Pradesh, India.

2. Assistant Professor, Department of Obstetrics and Gynecology, GSVM Medical College, Kanpur, Uttar Pradesh, India.

3. Post-graduate, Department of Obstetrics and Gynecology, GSVM Medical College, Kanpur, Uttar Pradesh, India.

\section{Manuscript Info}

\section{Manuscript History}

Received: 05 June 2017

Final Accepted: 07 July 2017

Published: August 2017

Key words:-

Awareness, Attitude, Hiv/Aids,

Knowledge, Mtct, Pregnant.

\section{Abstract}

Background- Prevalence of HIV/AIDS is highest among young people. HIV related stigma make people hesitant to get test done, thereby increasing risk of transmission of infection from pregnant mother to child.

Objective- This study aims to determine awareness, knowledge, attitude and misconceptions about HIV /AIDS in antenatal women.

Methods: A cross-sectional community based study was conducted on 904 pregnant women attending ANC clinic at GSVM Medical College, Kanpur U.P. from Jan 2016 - July 2016. Study tool consisted of a selfdeveloped, pretest questionnaire.

Results: Out of total 904 women only 496 (54.9\%) of them had heard of AIDS and level of awareness regarding HIV/AIDs was lower in women aged less than 20 years, illiterate, women resident of rural area and of low socio-economic status. Main source of information was media (51.6\%). Sexual intercourse was identified as major route of transmission (72.9\%) and mother to child transmission(MTCT) as least common known method (56\%). There were many misconceptions also. 401 women $(80.8 \%)$ realized AIDS as threat to human.

Conclusion: Although $54.9 \%$ pregnant women had heard of HIV/AIDS but level of complete knowledge about infection and MTCT was low. This is time to strengthen PMTCT program and to increase awareness of HIV/AIDS.

\section{Introduction:-}

HIV/AIDS is spreading worldwide at an alarming rate and become global pandemic. There are an estimated 21.17 lakhs people living with HIV/AIDS of which $6.54 \%$ are children ( $<15$ years) with an adult prevalence of $0.26 \%$ in 2015. Prevalence of HIV is highest among productive young people between the ages of 20 and 29 years; with $60 \%$ of new infection occurring in the 15-25 years age group ${ }^{2,3}$. Heterosexual transmissions account for $84 \%$ of cases In India and HIV in spreading rapidly in married women, who were previously considered to be at low risk ${ }^{4}$. It causes 
increase risk of transmission of infection from pregnant mother to child. So, prevention of mother to child transmission (PMTLT) program was launched to reduce the transmission of HIV infection from HIV infected mother to their offspring 5 .

HIV related stigma and discrimination remains an important barrier in effective fighting against HIV and AIDS epidemic. It results in people living with HIV/AIDS (PLWHA) being shunned by family and the community; stigmatization would make people hesitant to get test done, therefore more PLWHA are unaware that they are suffering from HIV/AIDS, and putting his/her sexual partners at risk of getting infection, due to lack of precautionary measures ${ }^{6}$.

Various government and non government agencies all working to raise awareness among people regarding HIV/AIDS. To stop the spread of HIV/AIDS, first phase of National AIDS control Programme (NACP-I) was launched by Government of India in 1992, Now NACP - IV is running.Inspite of lot of efforts, awareness and knowledge about HIV /AIDS is still inadequate among women; because they are not comfortable for talking about HIV, awareness programmes are not able to reach up to them and inaccurate information about the modes of transmission of HIV due to cultural and religious beliefs or lack of education.

However, treatment is available to delay progression of disease, yet there is no cure.Thus it is necessary to educate young people so that they can prevent themselves from getting infect. It is seen that pregnant women are much more receptive on health matters and assessment of awareness level in pregnant women is important because it helps to determine their knowledge and the impact of previous awareness and prevention efforts made by the government. Thus, with this background, the present study aims to determine awareness, knowledge and misconception about HIV /AIDS in antenatal women attending ANC clinic in tertiary care hospital.

\section{Material \& Methods:-}

A cross-sectional community based study was conducted on pregnant women attending ANC clinic at GSVM Medical College, Kanpur U.P. from Jan 2016 - July 2016. Study tool consisted of a self-developed, pretest questionnaire. Total pregnant women attended ANC clinic out of which 904 women were randomly selected, during their first antenatal visit at OPD in given period of study. Questionnaire included demographic information, awareness on HIV/AIDS, knowledge on mode of transmission, source of information and misconceptions about HIV /AIDS apart from routine history and examination only after explaining the purpose of the study and informed consent. The participants were not forced to answer any questions and they were free not to respond or partially respond to any question. Interview was conducted privately.

\section{Observations:-}

In this study, most of the women belonged to age group between 20-30 years (80.1\%) and had low literacy rates. Majority of women were hindu, housewife by occupation, of lower socio economic status and resident of urban area. In the present study, out of total 904 patients only $496(54.9 \%)$ of them had heard of AIDS and level of awareness regarding HIV/AIDs was lower in women aged less than 20 years, illiterate, housewife by occupation, women resident of rural area and belonging to low socio-economic status. Main source of information was media (51.6\%) followed by friends.

In current study sexual intercourse was identified as main route of transmission (72.9\%) followed by blood transfusion $(70.1 \%)$ and sharing needle $(61.3 \%)$. Mother to child transmission remained the least common known method of mode of transmission (56\%). There are many misconceptions regarding mode of transmission and taking food with HIV infected person found to be most common method of transmission. Although 368 women (74.2\%) knew that it could be prevented. Even 401 women (80.8\%) thought AIDS as threat to human.62.9\% wanted to check and $54.83 \%$ women wanted to discuss it with husband. Most women did not want to have more children and wanted to shorten breast feeding. 151 women (30.4\%) felt sympathetic to women suffering from HIV/AIDS although $7.6 \%$ women thought that women infected with AIDS should be isolated from society.

\section{Discussion:-}

Awareness is the key to prevention of HIV/AIDS. Like our study,Shrotri A et $\mathrm{al}^{7}$ and Bhalge $\mathrm{U}_{\text {et }} \mathrm{al}^{8}$ also reported that majority of antenatal women were literates, housewife and belongs to age group 20-30 years. 
Out of total 904 patients only 496 (54.9\%) of them had heard of AIDS. According to NFHS-3, 45\% of women have heard of HIV/AIDs in Uttar Pradesh and only 16\% women had comprehensive knowledge of HIV prevention and transmission ${ }^{9}$. Singh et $\mathrm{al}^{10}$ showed in their study that about $40 \%$ of pregnant women had heard of AIDS. In other studies done in rural Maharasthra ${ }^{11}$ and Tamilnadu ${ }^{12}$, it was observed that percentage of women who had heard of HIIV/AIDs was $92.4 \%$ and $72 \%$ respectively. In recent study of pregnant women in South Indian nearly all had heard of HIV/AIDs and one-third had general knowledge of the disease ${ }^{13}$.

In the present study, level of awareness regarding HIV/AIDs was lower in women aged less than 20 years, illiterate and housewife by occupation which is comparable to study done by SolatS et al ${ }^{14}$. According to NFHS-3 also, illiterate women had less awareness about HIV/AIDS in UP and maximum awareness was found in age group of 1524 years $(52.7 \%)^{9}$. In current study, women resident of rural area and belonging to low socio-economic status were having less awareness regarding HIV/ AIDS, which is comparable to study done by Shree V et $\mathrm{al}^{15}$. Similarly in study done by D. Balki, S. Lahiri in 13 State of India ${ }^{16}$, low level of knowledge and awareness were reported more among rural and illiterate women. Similarly in other studies also carried out in different part of India, higher education and socio-economic status associated with increase in awareness towards AIDS ${ }^{17,18,19}$. The statistically significant relationship between the level of education and knowledge of HIV/AIDS was also found in study by Bassey et $\mathrm{a}^{5}$.

This may be due to fact that women are hesitant to discuss about HIV/AIDS and this might be the reason behind some of them avoiding to answer the question about HIV/AIDS. Similarly study by D. Balki, S. Lahiri in 13 state of India it was observed that AIDS knowledge was more among those older than 20 years. In their study main source of information was media as it had played an important role in making people aware of HIV/AIDS with television rated as most popular media for awareness generation ${ }^{20}$. In NFHS-3 also, media specially television was main sources of information, ${ }^{9}$. ( as $81 \%$ women had heard of HIV/AIDs from TV ). Bhalge U et al ${ }^{8}$ and Shrotri A et al ${ }^{7}$ also reported television as main source of information. In study done in Maharasthra, Tamilnadu, Chandigarh also it was seen that major source of information about HIV AIDS was mass media ${ }^{11,12,21}$.

In current study sexual intercourse was identified as main route of transmission (72.9\%) followed by blood transfusion (70.1\%) and sharing needle (61.3\%). Similarly Shree V et al ${ }^{15}(68 \%)$, Bhalge U et al ${ }^{8}(84 \%)$ and Lal P et $\mathrm{al}^{22}(48.2 \%)$ also mentioned sexual contact as major cause. This agrees with a worldwide trend in which sexual intercourse is the route of transmission mostly known to respondents.

In Sevanan Murarjan et al study ${ }^{23}$, commercial sex workers were the main reason for transmission of HIV/AIDS followed by blood transfusion. In Shrotri A et al study ${ }^{7}$, knowledge of primary transmission and use of unsterile needle was over $75 \%$. Mother to child transmission of HIV was known by $56 \%$ women which is comparable to study done by Vijay Shree et al (60\%) and Bhalge U et al(58.6\% $)^{15,8}$. Bhalge et al also found knowledge of mother to child transmission and sharing of needle and syringe as mode of transmission is still low ${ }^{8}$. Breast feeding was least known mode of transmission (41.5\%) while in study done by Vijay Shree et al, 53\% respondents identified breast feeding as route of transmission ${ }^{15}$. In study by Bhalge et al, a large number of pregnant women did not know that breast feeding is associated with risk of transmission of $\mathrm{HIV}^{8}$.

It is important to note that number of women incorrectly stated that disease spreads through hugging/kissing in cheek (11.8\%), living (9.3\%) and sharing food with HIV infected person $(5.2 \%)$, by mosquito bite $(4.8 \%)$ and by sharing public toilets $(3.6 \%)$. There are also some misconception such as HIV could be transmited by a mosquito bite and sharing meal with an infected person noted by Bhalge et $\mathrm{l}^{8}$. Vijay Shree et al also reported that some women mentioned mosquito bite and sharing of food and clothes as mode of HIV/AIDS transmission ${ }^{15}$. According to Malleshappa et al also, some women incorrectly shared that the disease spreads through mosquito bites (17\%), public toilets (11\%) physical contact (kissing on cheeks $20 \%)^{24}$. In study done by Negi et al, $32 \%$ respondent thought hugging, kissing or wearing clothes of HIV/AIDS positive person; $36 \%$ believe that sharing food with a HIV infected person and even 56\% thought bites of mosquito and bed bug can transmit infection of HIV/AIDS. $74.2 \%$ women noted that it could be prevented ${ }^{25}$.

The present study reveal that $368(74.2 \%)$ had knowledge of at least one method as mean of prevention. Most common method known was condom use, followed by monogamous relationship and safe injection practices. In Shrotri et al study ${ }^{7}, 53 \%$ women was asked to mention at least one method of prevention. SevananMurajan et al studied that avoid commercial sex worker and multiple sex partner are the main measure to prevent HIV/AIDS 
followed by use of condom, avoid blood transfusion from HIV patients and infected needle played third risk ${ }^{23}$. Bhalge et al also reported that majority of women had knowledge about condom $(72.66 \%)$ as mean of protection followed by safe blood $(29.34 \%)^{8}$.

In current study $80.8 \%$ women realisedAIDS as threat to human which is comparable to study by Negi et al $(73.6 \%)^{25}$. Singh et $\mathrm{al}^{10}$ and Ambati et $\mathrm{al}^{26}$ had also revealed similar findings among educated pregnant women. $62.9 \%$ women agreed for compulsory testing of HIV in pregnancy while in study by Solat S et al ${ }^{14}$, only $3.87 \%$ subjects found its mandatory to both the partner for HIV testing before marriage and $4.2 \%$ found it necessary to test each individual for HIV infection. 77.4\% women don't want to have more children when they found HIV positive while in study by Solat S et al, $37.15 \%$ women believed that HIV infected females should never get conceived ${ }^{14}$.

In study by Malleshappa et al, only $12 \%$ subjects are willing to get tested for HIV. In current study, $30.4 \%$ feel sympathetic to PLHA and 7.7\% women believed that HIV /AIDS infected person should be isolated while $72.6 \%$ women did not think so. Malleshappa et al observed in his study that AIDS patients should isolated from the society, whereas about $26 \%$ of the respondents felt sympathetic towards PLHA ${ }^{24}$.

\section{Conclusion:-}

The level of complete knowledge about HIV/AIDS is very low although $54.9 \%$ pregnant women had heard about HIV/AIDS but still knowledge about MTCT was very sparse. Since awareness is the only key to the prevention of HIV/AIDS there is urgent need to increase awareness and knowledge about mode of transmission and prevention of HIV/AIDS, specially among the illiterate, rural and women belonging to low SES for which mass media can play an important role. It is time to strengthen PMTCT program to reduce the transmission of infection from infected mother to their offsprings as well as decrease the progression of disease. It is worthwhile to eliminate misconception and necessary to create suitable environment at community level to stimulate fear and guilt free discussion on the issue of HIV/AIDS \& condom.

Table1:-Correlation of socio-demographic parameters with awareness of HIV (n=904).

\begin{tabular}{|c|c|c|c|c|}
\hline \multicolumn{2}{|c|}{ Characteristics } & \multicolumn{3}{|c|}{ Awareness } \\
\hline \multirow[t]{4}{*}{1} & Age & $\begin{array}{c}\text { Number } \\
904\end{array}$ & $\begin{array}{c}\text { Yes } \\
496(54.9 \%)\end{array}$ & $\begin{array}{cl} & \text { No } \\
408(45.1 \%)\end{array}$ \\
\hline & $<20$ years & $64(7.1 \%)$ & $15(23.4 \%)$ & $49(76.6 \%)$ \\
\hline & 21-30 years & $724(80.1 \%)$ & $430(59.4 \%)$ & $294(40.6 \%)$ \\
\hline & $>30$ years & $116(12.8 \%)$ & $51(43.9 \%)$ & $65(56 \%)$ \\
\hline 2 & \multicolumn{4}{|c|}{ Education Status } \\
\hline & Illiterate & $480(53.1 \%)$ & $161(33.5 \%)$ & $319(66.5 \%)$ \\
\hline & Primary & $218(24.1 \%)$ & $149(68.3 \%)$ & $69(31.7 \%)$ \\
\hline & High School & $106(11.7 \%)$ & $93(87.7 \%)$ & $13(12.3 \%)$ \\
\hline & Secondary & $59(6.5 \%)$ & $52(88.1 \%)$ & $07(11.9 \%)$ \\
\hline & Graduate & $41(4.6 \%)$ & $41(100 \%)$ & $0(0 \%)$ \\
\hline \multirow[t]{5}{*}{3} & \multicolumn{4}{|c|}{ Occupation } \\
\hline & Housewife & $768(84.9 \%)$ & $382(49.7 \%)$ & $386(50.3 \%)$ \\
\hline & Skilled & $56(6.2 \%)$ & $44(78.6 \%)$ & $12(21.4 \%)$ \\
\hline & Unskilled & $44(4.9 \%)$ & $34(77.3 \%)$ & $10(22.7 \%)$ \\
\hline & Professional & $36(3.9 \%)$ & $36(100 \%)$ & 0 \\
\hline \multirow[t]{3}{*}{4} & \multicolumn{4}{|c|}{ Habitat } \\
\hline & Rural & $358(39.6 \%)$ & $130(36.3 \%)$ & $228(63.7 \%)$ \\
\hline & Urban & $546(60.4 \%)$ & $366(67.0 \%)$ & $180(33 \%)$ \\
\hline \multirow[t]{6}{*}{5} & \multicolumn{4}{|c|}{$\begin{array}{l}\text { Socio-economic status } \\
\end{array}$} \\
\hline & Upper & 0 & 0 & 0 \\
\hline & Middle & $8(0.8 \%)$ & $8(100 \%)$ & 0 \\
\hline & Lower Middle & $102(11.3 \%)$ & $78(76.5 \%)$ & $24(23.5 \%)$ \\
\hline & Upper lower & $342(37.8 \%)$ & $174(50.9 \%)$ & $168(49.1 \%)$ \\
\hline & Lower & $452(50.0 \%)$ & $236(52.2 \%)$ & $216(47.8 \%)$ \\
\hline \multirow[t]{2}{*}{6} & \multicolumn{4}{|c|}{ Religion } \\
\hline & Hindu & $792(87.6 \%)$ & $434(54.8 \%)$ & $358(45.2 \%)$ \\
\hline
\end{tabular}




\begin{tabular}{|c|c|c|c|c|}
\hline & Muslim & $96(10.6 \%)$ & $54(56.3 \%)$ & $42(43.7 \%)$ \\
\cline { 2 - 4 } & Others & $16(1.8 \%)$ & $8(50 \%)$ & $8(50 \%)$ \\
\hline
\end{tabular}

Table 2:- Knowledge about HIV / AIDS ( $\mathrm{n}=496)$.

\begin{tabular}{|c|c|c|}
\hline $\begin{array}{l}\text { 1. Source of information } \\
\qquad \text { Media } \\
\bullet \quad \text { Friends / Relative } \\
\bullet \quad \text { Medical Professional }\end{array}$ & $\begin{array}{c}256 \\
162 \\
78 \\
\end{array}$ & $\begin{array}{l}51.6 \% \\
32.7 \% \\
15.7 \%\end{array}$ \\
\hline $\begin{array}{l}\text { 2. Knowledge regarding mode of transmission } \\
\text { - Sexual intercourse } \\
\bullet \quad \text { Blood transfusion } \\
\bullet \quad \text { Sharing needle/syringe } \\
\text { - Mother to child transmission } \\
\text { Pregnancy } \\
\text { Delivery } \\
\text { Breast feeding }\end{array}$ & $\begin{array}{l}362 \\
348 \\
304 \\
278 \\
246 \\
278 \\
206\end{array}$ & $\begin{array}{l}72.9 \% \\
70.1 \% \\
61.3 \% \\
56.0 \% \\
49.6 \% \\
56.0 \% \\
41.5 \%\end{array}$ \\
\hline $\begin{array}{l}\text { 3. Misconceptions regarding mode of transmission } \\
\text { • Living with HIV infected person } \\
\text { - Taking food with HIV infected person } \\
\text { • Hugging / kissing on cheek } \\
\text { - mosquito bite } \\
\text { - Sharing utensils } \\
\text { - Sharing public toilets }\end{array}$ & $\begin{array}{l}46 \\
26 \\
59 \\
24 \\
18 \\
18 \\
\end{array}$ & $\begin{array}{c}9.3 \% \\
5.2 \% \\
11.8 \% \\
4.8 \% \\
3.6 \% \\
3.6 \% \\
\end{array}$ \\
\hline $\begin{array}{l}\text { 4. Knowledge regarding preventive measures } \\
\text { - Can HIV be prevented } \\
\text { Yes } \\
\text { No } \\
\text { Don't know } \\
\text { - Monogamous relationship } \\
\text { - Use of Condoms } \\
\text { - Safe injection practices } \\
\text { - Safe blood transfusion } \\
\text { - Avoid pregnancy }\end{array}$ & $\begin{array}{c}368 \\
58 \\
70 \\
360 \\
362 \\
60 \\
52 \\
58\end{array}$ & $\begin{array}{l}74.2 \% \\
11.7 \% \\
14.1 \% \\
72.6 \% \\
73.0 \% \\
12.1 \% \\
10.5 \% \\
11.7 \%\end{array}$ \\
\hline $\begin{array}{l}\text { 5. Knowledge regarding health services } \\
\bullet \quad \text { Availability of HIV testing facilities } \\
\bullet \quad \text { Necessity of HIV testing in pregnant women } \\
\bullet \quad \text { Availability of HIV treatment facilities }\end{array}$ & $\begin{array}{l}372 \\
298 \\
324 \\
\end{array}$ & $\begin{array}{l}75.0 \% \\
60.0 \% \\
65.3 \%\end{array}$ \\
\hline
\end{tabular}

Table 3:-Attitudes Towards HIV/AIDS \&PLWHA.

\begin{tabular}{|c|c|c|}
\hline Do you think AIDS is thread to humans & 401 & $80.8 \%$ \\
\hline $\begin{array}{l}\text { Do you wish to check } \\
\qquad \begin{array}{c}\text { Yes } \\
\text { No } \\
\text { Don't know }\end{array}\end{array}$ & $\begin{array}{c}312 \\
102 \\
82\end{array}$ & $\begin{array}{l}62.9 \% \\
20.6 \% \\
16.5 \%\end{array}$ \\
\hline If $\mathrm{HIV}+$, discuss with & $\begin{array}{c}272 \\
98 \\
78 \\
48\end{array}$ & $\begin{array}{l}54.8 \% \\
19.8 \% \\
15.7 \% \\
9.7 \%\end{array}$ \\
\hline $\begin{array}{c}\text { If you know HIV in your blood wants more children } \\
\text { Yes } \\
\text { No } \\
\text { Don't know }\end{array}$ & $\begin{array}{c}48 \\
384 \\
64\end{array}$ & $\begin{array}{l}9.7 \% \\
77.4 \% \\
12.9 \%\end{array}$ \\
\hline
\end{tabular}




\begin{tabular}{|c|c|c|}
\hline If you found HIV is your blood shorten breast feeding & 282 & $56.9 \%$ \\
Yes & 136 & $27.4 \%$ \\
No & 78 & $15.7 \%$ \\
Don't know & 38 & \\
Yes & 360 & $72.6 \%$ \\
No & 98 & $19.8 \%$ \\
Don't know & & \\
Yes & 151 & $30.4 \%$ \\
No & 38 & $7.6 \%$ \\
Don't know & 307 & $61.9 \%$ \\
\hline
\end{tabular}

\section{References:-}

1. National AIDS Control Organization (NACO), Government of India (GOI) Annual Report 2015-16. http://www.nacoonline.org. Accessed 2006.

2. National AIDS control organization (NACO). Annual HIV Sentinel surveillance Country Report 2006. Available from: http://www.nacoonline .org/upload/[accessed on 2010 Mar 16].

3. US AIDS international development (USAID).India country profile (HIV/AIDS),2008. Available from: http://www.usaid.gov/locations/asia/ countries/india [accessed on 2010 march 16]

4. ChatterjeeN,Hosain GMM. Perceptions of risk and behavior change for prevention of HIV among married women in Mumbai, India J Health Popul Nutr,24(1),2006;55-58.

5. Bassey E.A.,Abasiubang F, Ekanem U, Abasiatai. Awareness and knowledge of HIV/AIDS at booking among antenatal clinic attendees in UYO, Nigeri.Int.J.med.med.sci,1(8),2009;334-338.

6. Report on the global HIV/AIDS epidemic. Available from:http://www.unaids.org/epidemic update/report/index.html (accessed on 2011 jan 15).

7. Shrotri A, Shankar AV, Sutar S, Joshi A, Suryawanshi N, Pisal H et al.Awareness of HIV/AIDS and household environment of pregnant women in Pune, India. International journal of STD and AIDS,14,2003,835-839.

8. Bhalge U.U, Khakse GM, Brahmapurkar KP, Thorat R, Shrote VK. Awareness Regarding HIV/AIDS in ANC Client in tribal district of central India. Journal of Dental and Medical Sciences;volume 2, Issue 4(nov.-dec 2012):44-49.

9. Uttar Pradesh, NFHS-3,2005-2006. Available at http://health.nic.in/NFHS-3 [accessed May 5,2009].

10. Singh S, Fukuda H, Ingle GK and Tartara K. Knowledge, attitude, the perceived risks of infection and sources of information about HIV/AIDS among pregnant women in a urban population of Delhi. J Commun Disea;34(1):23-34

11. National Behavioural surveillance survey-general population. National AIDS Control organization, Ministy of health and family welfare, Government of India 2006:36. Page no. 32,42-46,50,108.

12. Subramanian T, Gupte MD, Ezhil R. AIDS: An understanding in rural women of South India. Indian Journal of sexually transmitted diseases, 2007;28(1):10-14.

13. Brown H, Vallabhaneni S, Solomon S, et al. Attitudes towards prenatal HIV testing and treatment among pregnant women in southern India. Int J AIDS, 12,2001,390-394.

14. Solat S, Velhal GD, MahajanH,RaoA,Sharma B. Assessment of Awareness about HIV/AIDS and Operationalization of Interventions in Rural Population of Raigaddistrict,India. International Journal of Scientific and Research Publications,volume 2,issue 11,November 2012:1-14.

15. Shree V, Prasad RR. Awareness of HIV/AIDS amongst Pregnant Women of Rural Areas, Patna: A Community based study. International Journal of Science and Research, vol.4 issue 8,August 2015:106-110.

16. Balk D, Lahiri S. Awareness and knowledge of AIDS among Indian women: Evidence from 13 states. Health Transit Rev. 1997; 7:421-465.

17. Jacob KS, Jayakumari H, Jacob K John and Jacob John T. Awareness of AIDS in India: effect of public education through the mass media. BMJ 1989; 229:721.

18. Porter SB. Public knowledge and attitudes about AIDS among adults in Calcutta, India. AIDS Care 1993;5:16976.

19. Poddar SB. Public knowledge and attitudes about AIDS among adults in Calcutta, India. AIDS Care 1993;5:169-76. 
20. Lahiri S, Balk D, Pathak.KB. Women in thirteen states have little knowledge of AIDS. NatlFam Health Surv Bull.1995 oct;(2):1-4.

21. Bhatia V,Puri S, Mangat C \& Swami H. An intervention study to enhance AIDS awareness among underprivileged population in Chandigarh. The Internet Journal of Health [Internet]. 2010;11(1). Available at: http://www.ispub.com/journal/the internet journal of health/volume 11 number 1 10/article/an-interventionstudy-to-enhance-aids-awareness-among-underprivileged-population-in chandigarh-1.htm.

22. Lal P, Nath A, Bandhan S, Ingle GK. The study of awareness about HIV/AIDS among senior secondary school children of Delhi. Indian Journal of community medicine, 33(3),2010,190-192.

23. Murajan S, Saberrimuthis, Pongiya V, Desigan CG. Awareness about HIV/AIDS among adolescent boys in tribal villages of nilgiri district south India. Humanity and social sci. J;5(1):63-67.

24. Malleshappa K, Krishna S, Shashikumar. Awareness and attitude of youth toward HIV/AIDS in rural southern India. Biomedical Research 2012; 23(2):241-246.

25. Negi KS, Khandpal SD, Kumar A,Kukreti M. Knowledge,Attitude and perception about HIV/AIDS among Pregnant Women in rural area of Dehradun.JK Science, 2006;vol.8(3):133-138.

26. Ambati BK, Ambati J and Rao AM. Dynamics of knowledge and attitudes about AIDS among the educated in Southern India.AIDS Care 1997;9:319-30. 